Open Access

\title{
Deletion of Wntless in myeloid cells exacerbates liver fibrosis and the ductular reaction in chronic liver injury
}

Katharine M. Irvine ${ }^{1 *}$, Andrew D. Clouston ${ }^{1}$, Victoria L. Gadd ${ }^{1}$, Gregory C. Miller ${ }^{1}$, Weng-Yew Wong ${ }^{1}$, Michelle Melino ${ }^{2}$, Muralidhara Rao Maradana ${ }^{3}$, Kelli MacDonald ${ }^{2}$, Richard A. Lang ${ }^{4}$, Matthew J. Sweet ${ }^{5}$, Antje Blumenthal ${ }^{3,6+}$ and Elizabeth E. Powell ${ }^{1+}$

\begin{abstract}
Background: Macrophages play critical roles in liver regeneration, fibrosis development and resolution. They are among the first responders to liver injury and are implicated in orchestrating the fibrogenic response via multiple mechanisms. Macrophages are also intimately associated with the activated hepatic progenitor cell (HPC) niche or ductular reaction that develops in parallel with fibrosis. Among the many macrophage-derived mediators implicated in liver disease progression, a key role for macrophage-derived Wnt proteins in driving pro-regenerative HPC activation towards a hepatocellular fate has been suggested. Wnt proteins, in general, however, have been associated with both pro- and anti-fibrogenic activities in the liver and other organs. We investigated the role of macrophage-derived Wnt proteins in fibrogenesis and HPC activation in murine models of chronic liver disease by conditionally deleting Wntless expression, which encodes a chaperone essential for Wnt protein secretion, in LysM-Cre-expressing myeloid cells (LysM-Wls mice).

Results: Fibrosis and HPC activation were exacerbated in LysM-Wls mice compared to littermate controls, in the absence of an apparent increase in myofibroblast activation or interstitial collagen mRNA expression, in both the TAA and CDE models of chronic liver disease. Increased Epcam mRNA levels paralleled the increased HPC activation and more mature ductular reactions, in LysM-Wls mice. Increased Epcam expression in LysM-Wls HPC was also observed, consistent with a more cholangiocytic phenotype. No differences in the mRNA expression levels of key pro-inflammatory and pro-fibrotic cytokines or the macrophage-derived HPC mitogen, Tweak, were observed. LysM-Wls mice exhibited increased expression of Timp1, encoding the key Mmp inhibitor Timp1 that blocks interstitial collagen degradation, and, in the TAA model, reduced expression of the anti-fibrotic matrix metalloproteinases, Mmp12 and Mmp13, suggesting a role for macrophage-derived Wnt proteins in restraining fibrogenesis during ongoing liver injury.
\end{abstract}

Conclusion: In summary, these data suggest that macrophage-derived Wnt proteins possess anti-fibrogenic potential in chronic liver disease, which may be able to be manipulated for therapeutic benefit.

Keywords: Liver fibrosis, Ductular reaction, Macrophages, Matrix remodelling, TAA, CDE

\footnotetext{
* Correspondence: katharine.irvine@uq.edu.au

${ }^{\dagger}$ Equal contributors

${ }^{1}$ Centre for Liver Disease Research, School of Medicine, The University of

Queensland, Translational Research Institute, 37 Kent St, Brisbane 4102,

Australia

Full list of author information is available at the end of the article
}

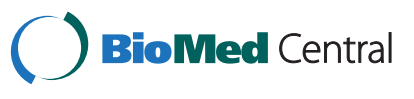

(c) 2015 Irvine et al. Open Access This article is distributed under the terms of the Creative Commons Attribution 4.0 International License (http://creativecommons.org/licenses/by/4.0/), which permits unrestricted use, distribution, and reproduction in any medium, provided you give appropriate credit to the original author(s) and the source, provide a link to the Creative Commons license, and indicate if changes were made. The Creative Commons Public Domain Dedication waiver (http://creativecommons.org/publicdomain/zero/1.0/) applies to the data made available in this article, unless otherwise stated. 


\section{Background}

Regardless of their aetiology, chronic liver diseases (CLDs) share a common pathological mechanism, liver-injury stimulated fibrosis, which, if progressive, can lead to cirrhosis, liver failure, and cancer. The inflammatory response to chronic injury, mediated by multiple parenchymal and non-parenchymal cells, plays critical roles in fibrogenesis. Like inflammation, fibrosis is an adaptive response to liver injury that, when appropriately regulated, facilitates tissue repair. How these protective responses become maladaptive and the interplay between fibrogenesis and repair, in the context of chronic injury and inflammation, is not well understood. Clinical observations and experimental models suggest that liver fibrosis is a dynamic, bidirectional process with the capacity for recovery even at advanced stages [1]. With no therapies available to prevent or treat liver fibrosis, better understanding of the mechanisms of fibrosis and repair and the role of inflammatory cells and mediators is crucial to developing new therapeutic approaches.

In a healthy liver, injured parenchymal cells can be regenerated through division of mature epithelial cells (hepatocytes and bile duct-forming cholangiocytes). Following severe or chronic injury, hepatocyte regeneration is impaired and an alternative regenerative pathway involving hepatic progenitor cells (HPCs) can be activated, which is associated with the development of ductular reactions (DRs) and progressive fibrosis, both in humans and mouse models of CLD [2-4]. HPCs are thought to be bipotential, capable of proliferation and differentiation into hepatocytes, to replace injured cells or along the 'ductular' cholangiocyte lineage. Although capable of differentiation into hepatocytes and cholangiocytes under clonogenic conditions in vitro, the extent to which HPCs directly replace epithelial cells to regenerate the liver is controversial [5-7]. The contribution of HPCs to liver regeneration in mouse models likely depends on the extent to which epithelial self-renewal is impaired. Indeed, it was recently demonstrated that HPC activation in the setting of near total hepatocyte death or senescence was necessary for survival [7]. DRs correlate with the extent of liver fibrosis and may be postulated to represent a failed attempt to regenerate the liver, but the causal relationship between DRs and fibrosis remains to be established. HPCs are intimately associated with fibrogenic activity, however, as they exist in a niche composed of myofibroblasts, macrophages and other leukocytes and extracellular matrix components. Both cellular and matrix components of the niche shape HPC activation and fate, and HPCs, in turn, influence myofibroblasts and inflammatory cells.

Macrophages play critical roles in liver regeneration, fibrosis development and resolution and are prominent features of the fibrotic scar and DR niche [8-11]. Macrophages have been shown to play a dichotomous role in the context of liver fibrosis, as they play a pro-fibrogenic role during the development of fibrosis whereas macrophage expression of matrix metalloproteinases and proangiogenic factors crucially contributes to the resolution of fibrosis during recovery from liver injury $[10,12]$ and potentially even during ongoing injury [13]. Macrophagederived factors, including Wnt proteins, are also directly implicated in controlling HPC proliferation, differentiation and invasion into the parenchyma [14-16]. Macrophage ablation reduced DR proliferation and expansion in several models of CLD [10, 16] and, strikingly, injection of macrophages caused transient TWEAK-dependent HPC activation in healthy mice [15].

HPC activation during injury appears to recapitulate liver epithelial cell development from hepatoblasts during embryogenesis and involves reactivation of developmental cell signalling pathways, including Wnt, Notch and Hedgehog [17]. Wnt signalling drives hepatocellular differentiation during development [18], and a similar function for Wnt proteins ('Wnts') during chronic liver injury has been suggested [14]. In contrast, macrophage-derived Wnt7b was recently shown to drive cholangiocarcinoma growth [19], highlighting the complex role of Wnt signalling in chronic liver disease. Inflammatory cytokines (e.g. IL-6, TNF, LT $\beta$, IFN $\gamma$ ) [20-23], injury-induced growth factors (e.g. TWEAK [24]) and extracellular matrix components (e.g. collagen, laminin and fibronectin $[25,26]$ ) are also implicated in regulating HPC proliferation and fate.

Wnts comprise a family of 19 secreted glycoproteins that activate target cells via $\beta$-catenin and $\beta$-cateninindependent pathways to regulate cell proliferation, differentiation and migration during development and homeostasis, including in multiple adult stem cell niches [18]. The pleiotropic targets and biological effects of Wnt signalling in the liver are not well understood. A loss-offunction mutation in the LRP6 gene, encoding a Wnt coreceptor, was recently associated with human nonalcoholic fatty liver disease [27]. Introduction of this mutation in mice caused steatohepatitis via a $\beta$-cateninindependent pathway, which was rescued by therapeutic administration of Wnt3a [27]. $\beta$-catenin signalling is implicated in liver repair and fibrogenesis, but the extent to which this is Wnt-dependent is not clear, as $\beta$-catenin stabilisation also occurs downstream of non-Wnt growth factors, such as hepatocyte growth factor [28]. In patients and mice with acute liver failure, $\beta$-catenin activation correlated with increased liver regeneration and (in patients) precluded the need for transplantation [29]. Multiple studies in rodent models of CLD have also suggested a role for $\beta$-catenin signalling in chronic liver injury, including driving HPC proliferation and differentiation [30-34]. By contrast, Wnt/ß-catenin signalling in fibroblasts was reported to be pro-fibrotic in systemic sclerosis, skin, lung, liver and kidney 
disease [35-38]. The cellular source and type of Wnt proteins expressed in response to injury and their target cells may determine whether tissue regeneration or fibrosis occurs. Macrophage- but not epithelial-derived Wnts contributed to liver regeneration after partial hepatectomy [39]; however, the role of macrophagederived Wnts in chronic liver disease, in particular in the HPC niche, is unknown. In the current study, we investigated the contribution of macrophage-derived Wnts to HPC activation and fibrogenesis during chronic liver disease. To do so, we examined the phenotype of mice with myeloid-targeted deletion of Wntless (Wls), encoding the chaperone Wls required for Wnt secretion [40]. Mice with Wls-deficient macrophages exhibited enhanced ductular reactions and fibrosis in two murine models of chronic liver disease. Our data are consistent with roles for macrophage-derived Wnts in HPC maturation and matrix remodelling to restrain net collagen deposition during chronic liver disease progression.

\section{Results}

Myeloid-specific Wls knockout does not affect liver macrophage abundance or localisation

To investigate the contribution of macrophage-derived Wnt proteins to inflammation, HPC activation and fibrosis, we generated mice deficient in Wls expression in myeloid cells by crossing Wls-loxp mice [40] with LysM-Cre mice [41] for 4-10 generations. Wls knockout in macrophages was confirmed by qPCR for Wls in bone marrow-derived macrophages (Additional file 1:
Figure S1A). LysM-Wls (Cre+) mice and littermate controls (Cre-) were administered thioacetamide (TAA, $300 \mathrm{mg} / \mathrm{L}$ ) in drinking water for 12 weeks as a model of chronic liver injury. Reduced Wls expression in F4/80+ liver cells sorted by flow cytometry was confirmed by qPCR (Additional file 1: Figure S1B-E). By contrast, Wls expression in Epcam+ cells, sorted by flow cytometry, was comparable between untreated $\mathrm{Cre}+$ and Cre- animals, confirming the specificity of targeting (Additional file 1: Figure S1F). Consistent with a recent report [39], LysMWls mice were viable and livers were histologically normal. Wls deficiency did not affect the number or localisation of liver macrophages in control or TAA-treated mice, as assessed by immunohistochemistry and image analysis for F4/80 and qPCR for Emrl (encoding the F4/ 80 antigen) in whole liver (Fig. 1). To determine which Wnt proteins are expressed by liver macrophages, we conducted a PCR for a panel of Wnt ligands. Wnt3a, Wnt5a, $W n t 7 a, W n t 7 b$ and $W n t 1$ mRNAs were below the limit of detection in F480+ cells from control or TAA-treated mice; however, Wnt4 and Wnt6 were robustly detected but not significantly altered by TAA treatment or genotype (Additional file 1: Figure S1G-H).

\section{Reduction in Wnt/ $\beta$-catenin signalling during liver injury in mice with Wls-deficient macrophages}

In healthy livers, $\beta$-catenin localised to hepatocyte membranes and bile duct epithelia, whereas after 12 weeks TAA treatment, $\beta$-catenin stained hepatocyte membranes and some nuclei, as well as HPC, in both LysM-Wls mice
A

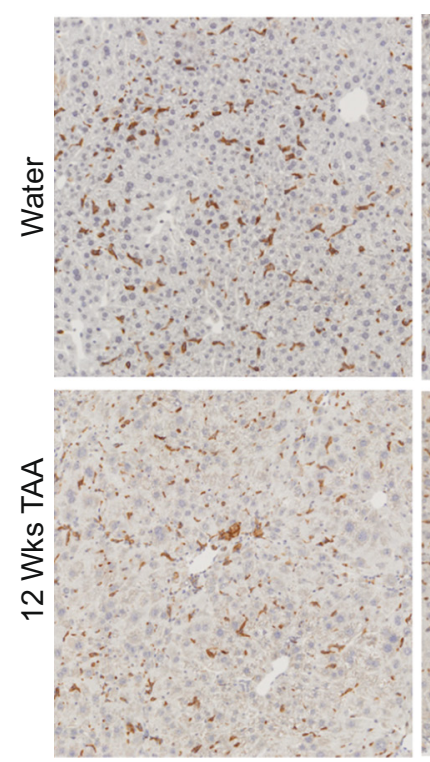

LysM-Wls

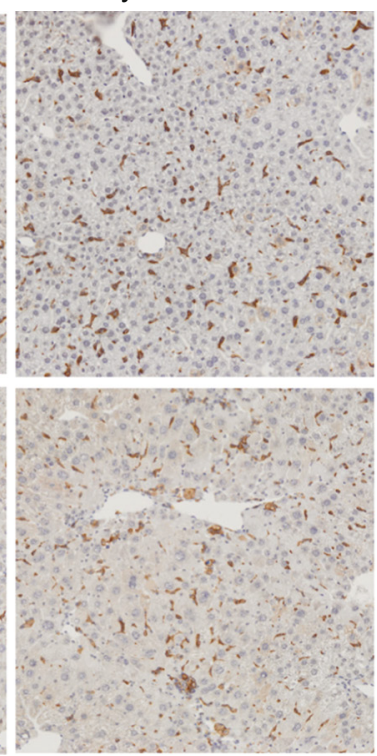

B

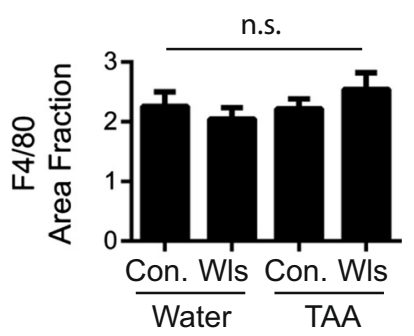

C

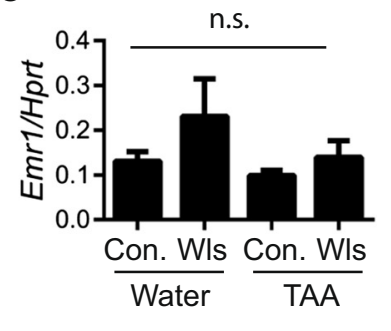

Fig. 1 LysM-Wls depletion does not affect macrophage abundance and localisation. F4/80+ liver macrophage localisation (representative stain, 5x original magnification) (a). Quantification of F4/80+ staining (b) and whole liver Emr1 (encoding the F4/80 antigen) expression (c) in control and LysM-WIs mice treated with water or TAA for 12 weeks. Data represent mean + SEM from 5 to 12 mice from 4 independent experiments. n.s. non-significant 
and littermate controls (Fig. 2a). Whilst no clear difference in $\beta$-catenin expression or localisation in injured mice was discernible, expression of the Wnt/ $\beta$-catenin target gene, Axin2, was elevated in livers from TAA-treated control mice but not LysM-Wls mice (Fig. 2b), consistent with a reduction in $\mathrm{Wnt} / \beta$-catenin signalling in LysM-Wls mice during liver injury. Whole liver expression of the Wnt/ $\beta$ catenin target genes Ccnd2 and Numb, which has previously been suggested to contribute to HPC hepatocellular fate determination [14], was not significantly different between genotypes, although there was a trend towards reduced Numb expression in LysM-Wls mice (Fig. 2c and data not shown).

\section{Wls depletion in macrophages exacerbates TAA-induced hepatic progenitor cell activation and fibrosis}

After 12 weeks of TAA treatment, LysM-Wls mice exhibited increased HPC activation, frequently associated with mature ductular reactions, which were not observed in littermate controls (pan-keratin staining, Fig. 3a, b). This was associated with increased fibrosis (Picro-Sirius red staining, Fig. 3c-e). Female mice were used in this study because we observed that TAA-induced HPC activation and fibrosis were more severe in females than males, however Wls deficiency in macrophages similarly exacerbated the DR and fibrosis in male mice (Additional file 2: Figure S2). The increased DR and fibrosis was not explained by increased susceptibility to TAA-induced injury, as liver injury was comparable in LysM-Wls mice and littermate controls, as assessed by serum ALT and liver histology (Fig. $4 \mathrm{a}-\mathrm{c}$ ). The expression of the key pro-inflammatory cytokines $\operatorname{Tnf}$ and Il6 that are produced by macrophages and other cell types in response to liver injury and play critical roles in liver inflammation, fibrosis and HPC activation
$[20,22,42]$ was not significantly different between LysM-Wls and littermate controls (data not shown). Despite the increase in fibrosis in LysM-Wls mice, mRNA levels of the key interstitial collagens contributing to liver fibrosis [43], Col1a1, Colla2 and Col3a1, were comparable between LysM-Wls and littermate controls (Fig. 5a-c). Although mRNA expression of Sma, which encodes smooth muscle actin, was comparable between genotypes (data not shown), there was a trend towards increased Sma protein expression in LysM-Wls mice (Fig. 5d, e), suggesting an increase in myofibroblast activation in these mice. Nevertheless, mRNA expression of the pro-fibrogenic cytokines $T g f b$ and $C \operatorname{tg} f$ [44] that play key roles in myofibroblast activation did not differ between genotypes (Fig. 5f, g).

\section{Hepatic progenitor cells express an immature profile in mice with Wls-deficient macrophages}

Paralleling the ductular reaction, Epcam (Tacstd1) liver mRNA levels were elevated in LysM-Wls mice compared to littermate controls (Fig. 6a), whereas the expression of the biliary keratin, Krt19, did not differ. Epcam is a cell surface glycoprotein expressed on tissue stem cells with regenerative capacity and is normally downregulated upon terminal differentiation [45]. To investigate the effects of macrophage-derived Wnts on HPC gene expression, we sorted Epcam+ cells from the liver non-parenchymal fraction to enrich for HPC. Expression of Epcam itself was increased in Epcam+ cells from TAA-treated LysM-Wls mice compared to littermate controls (Fig. 6b). Trop2 (Tacstd2), which encodes an Epcam-related protein reported to be specifically induced in HPC upon liver injury [46], was elevated in TAA-treated control mice and hyper-induced in LysM-Wls mice (Fig. 6c). We investigated

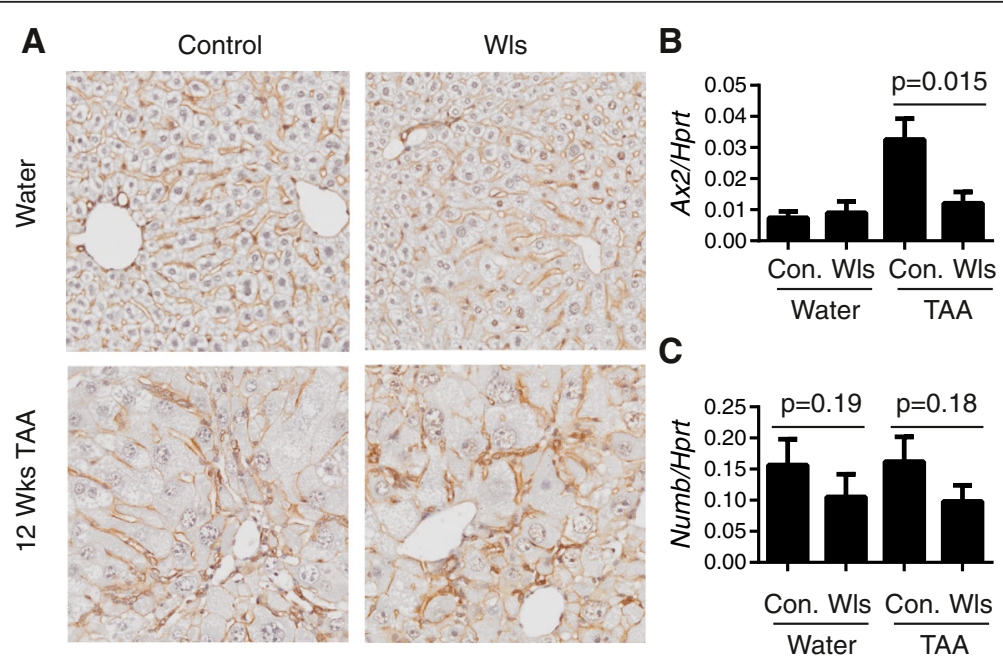

Fig. 2 Reduced W/s expression in macrophages from LysM-Wls mice is associated with reduced $\beta$-catenin target gene expression. a $\beta$-Catenin staining (representative, 10x original magnification) and whole liver expression of $\mathbf{b}$ Axin2 and $\mathbf{c}$ Numb in control and LysM-Wls mice treated with water or TAA for 12 weeks. Data represent mean+/-SEM of 5-12 mice from 4 independent experiments 


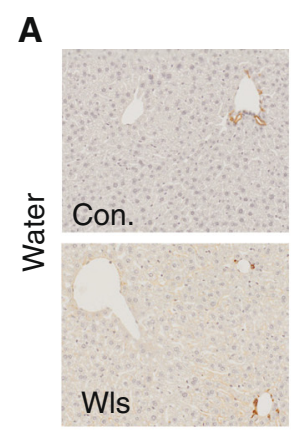

B

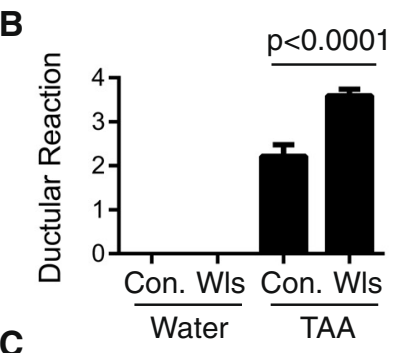

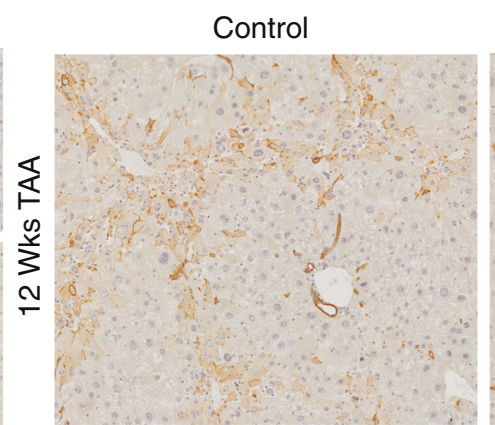

\section{D}

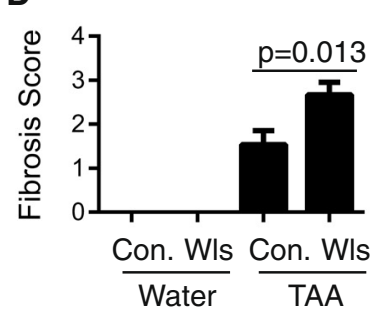

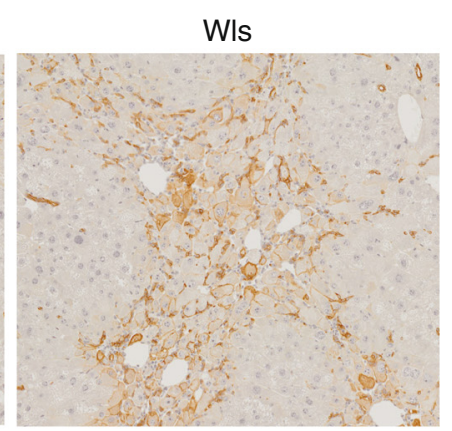

$E$

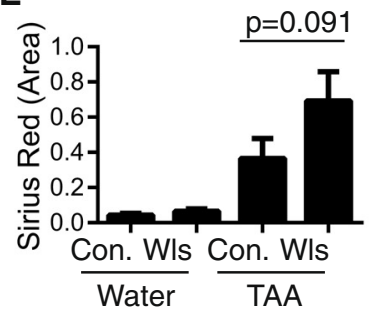

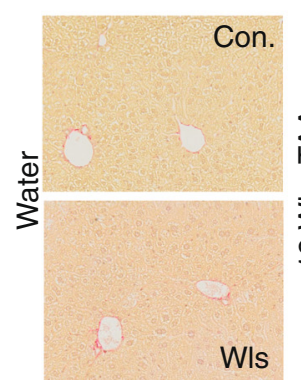

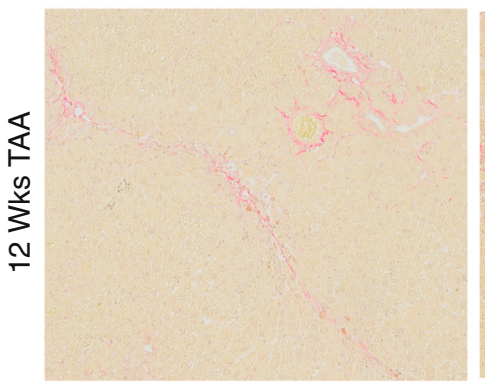

Control

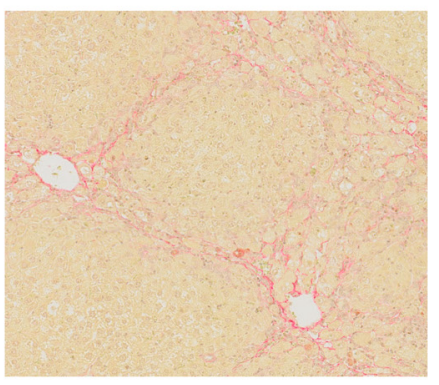

Wis

Fig. 3 Increased ductular reaction and fibrosis in LysM-WIs mice. a Representative CKWSS staining and $\mathbf{b}$ ductular reaction grade in livers from 12-week water- and TAA-treated control and LysM-WIs mice. $\mathbf{c}$ Representative Picro-Sirius Red staining, $\mathbf{d}$ fibrosis score and $\mathbf{e}$ collagen proportionate area in livers from water- and 12-week TAA-treated control and LysM-WIs mice. Data represent mean + SEM of 8-17 mice from 4 independent experiments

the expression of the Notch target gene Hey1 and the Wnt/ $\beta$-catenin target genes Axin2 and Numb in Epcam+ cells, as the Notch and Wnt/ $\beta$-catenin pathways have previously been suggested to have opposing roles in determining HPC fate [14, 17], to provide evidence for direct effect of macrophage-derived Wnts on HPC, however these genes were only marginally detected in sorted cells (data not shown).

\section{Macrophage metalloproteinase expression is reduced in TAA-treated LysM-Wls mice}

Macrophage production of the HPC mitogen, Tweak, has been implicated in driving HPC proliferation [15, 24]. Although TAA inducible, Tweak expression did not differ in whole liver or flow cytometry-sorted F4/80+ cells from control and LysM-Wls mice (Fig. 7a, b). As in whole liver, expression of the pro-inflammatory cytokines, Il6 and Tnf, and the pro-fibrotic cytokine, $T g f b$, did not differ between
LysM-Wls and control macrophages (data not shown). Since macrophages play a key role in matrix remodelling, we also examined the expression of key matrix remodelling factors implicated in liver fibrosis and repair [47]. We found myeloid deletion of Wls impaired injury-mediated upregulation of Mmp13 (encoding the key interstitial collagenase in rodents, Mmp13) and Mmp12 (encoding the elastase Mmp12) mRNAs in whole liver and purified F4/ $80+$ cells (Fig. $7 \mathrm{c}-\mathrm{f}$ ). $M m p 2$ and $M m p 8$ were induced in TAA-injured livers but not differentially expressed in Wlsdeficient and control mice, whereas no alteration in liver or macrophage $M m p 9$ expression was observed (data not shown). Furthermore, in TAA-treated LysM-Wls mice, the expression of Timp1, encoding the key Mmp inhibitor Timp1 that blocks interstitial collagen degradation [1], was higher compared to littermate controls (Fig. 7g). These data are consistent with the hypothesis that fibrolysis, as well as fibrogenesis, is dynamically regulated during 


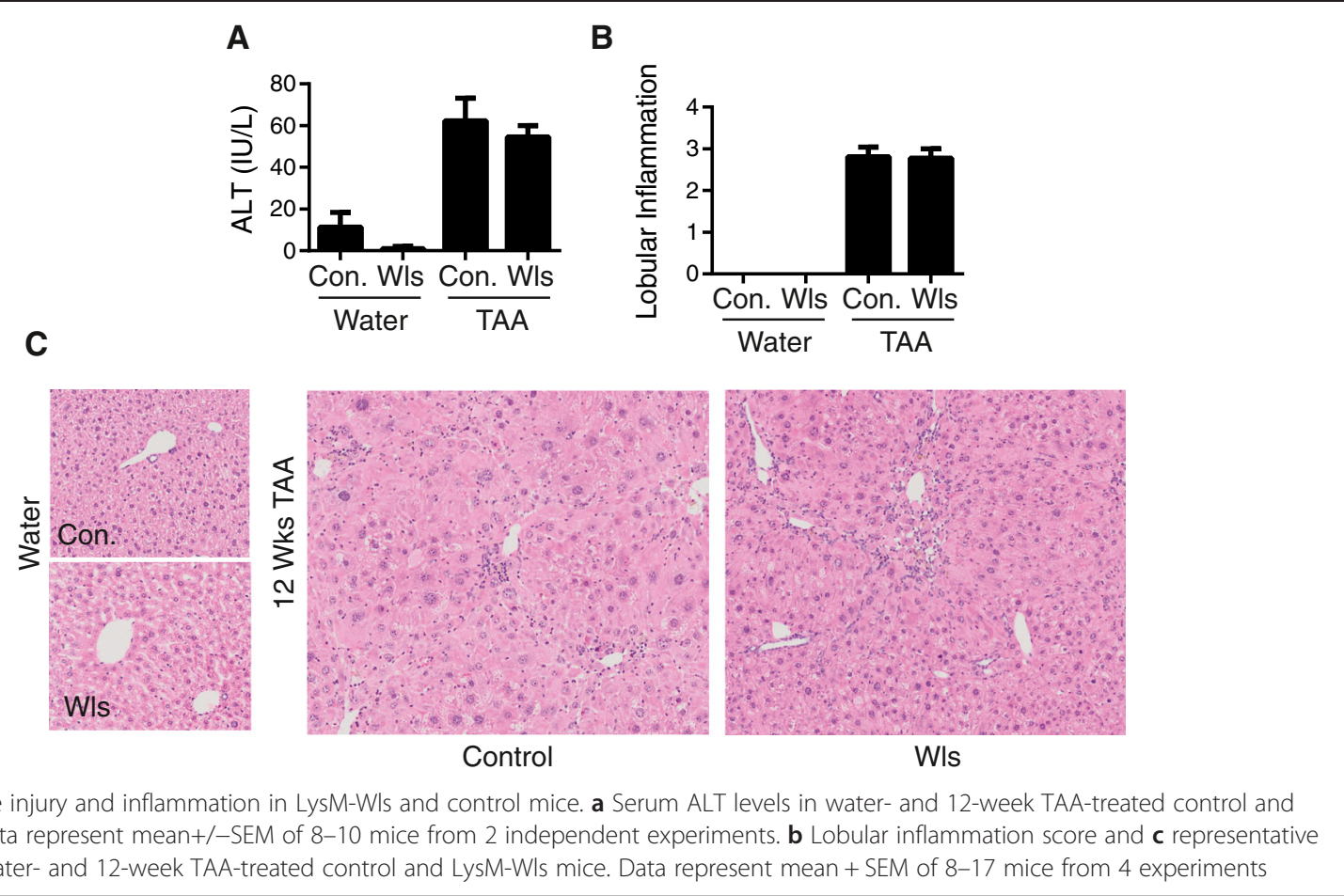

TAA-mediated liver injury and suggest that macrophagederived Wnt proteins promote matrix remodelling, via Mmp13 and Mmp12, potentially restraining fibrosis.

\section{Wls depletion in macrophages exacerbates CDE-induced hepatic progenitor cell activation and fibrosis}

To determine whether macrophage-derived Wnts contribute to the regulation of HPC activation and fibrogenesis in multiple contexts of liver injury, we employed an alternative model of liver injury and fibrosis. The cholinedeficient ethionine-supplemented (CDE) diet induces a robust DR but a different pattern of fibrosis to TAA [48]. Liver injury and fibrosis were also more severe in female mice than male mice in this model (data not shown). Similar to the TAA model, HPC activation and fibrosis were exacerbated in CDE-treated LysM-Wls mice compared to littermate controls, in the absence of alterations in whole liver Col1a1, Col1a2, Col3a1, Sma and Il6 expression between LysM-Wls mice and littermate controls (Additional file 3: Figure S3A-E and data not shown). Epcam expression was elevated in CDE-treated LysM-Wls mice, in whole liver and Epcam+ cells (Additional file 3: Figure S3F, G), suggesting similar alterations in HPC phenotype in both models. As in the TAA model, Timp1 mRNA expression was increased in CDEtreated LysM-Wls mice compared to littermate controls (Additional file 3: Figure S3I); however, Mmp13 was not detectable in the majority of CDE-treated mice and there was no difference in Mmp12, Mmp8, Mmp2 or Mmp9 expression (data not shown). Wnt4 and Wnt6 were expressed in macrophages from CDEtreated mice, regardless of genotype (data not shown).

\section{Discussion}

Macrophages contribute to the dynamic interplay between liver inflammation, fibrosis and regeneration via multiple mechanisms, at different locations and different disease stages. Inflammatory, bone marrow-derived monocytes infiltrate the liver in response to injury, where they are dynamically reprogrammed, depending on the nature and chronicity of the injury [10, 49-52]. Macrophages are among the earliest responders to liver injury, having roles in phagocytosis of apoptotic and necrotic cells and releasing soluble mediators, such as TNF and IL-6, that orchestrate inflammatory and ultimately pro-fibrogenic responses to chronic injury. Macrophages are also prominent components of the hepatic progenitor cell niche, which is closely associated with liver fibrogenesis [2, 8, 9] and repair; although the fate relationships among hepatocytes, cholangiocytes and HPC and the contribution of $\mathrm{HPC}$ to liver fibrosis and regeneration are controversial [5-7, 53-55]; and the factors determining their activation and differentiation are not well understood. Wnt proteins, potentially derived from macrophages, have been suggested to promote liver regeneration by driving HPC hepatocellular differentiation [14, 17, 32], which could theoretically ameliorate liver fibrosis by promoting regeneration. Wnt proteins, however, constitute a large family of proteins that have been variously attributed pro- and anti-fibrogenic properties [35-38] and 

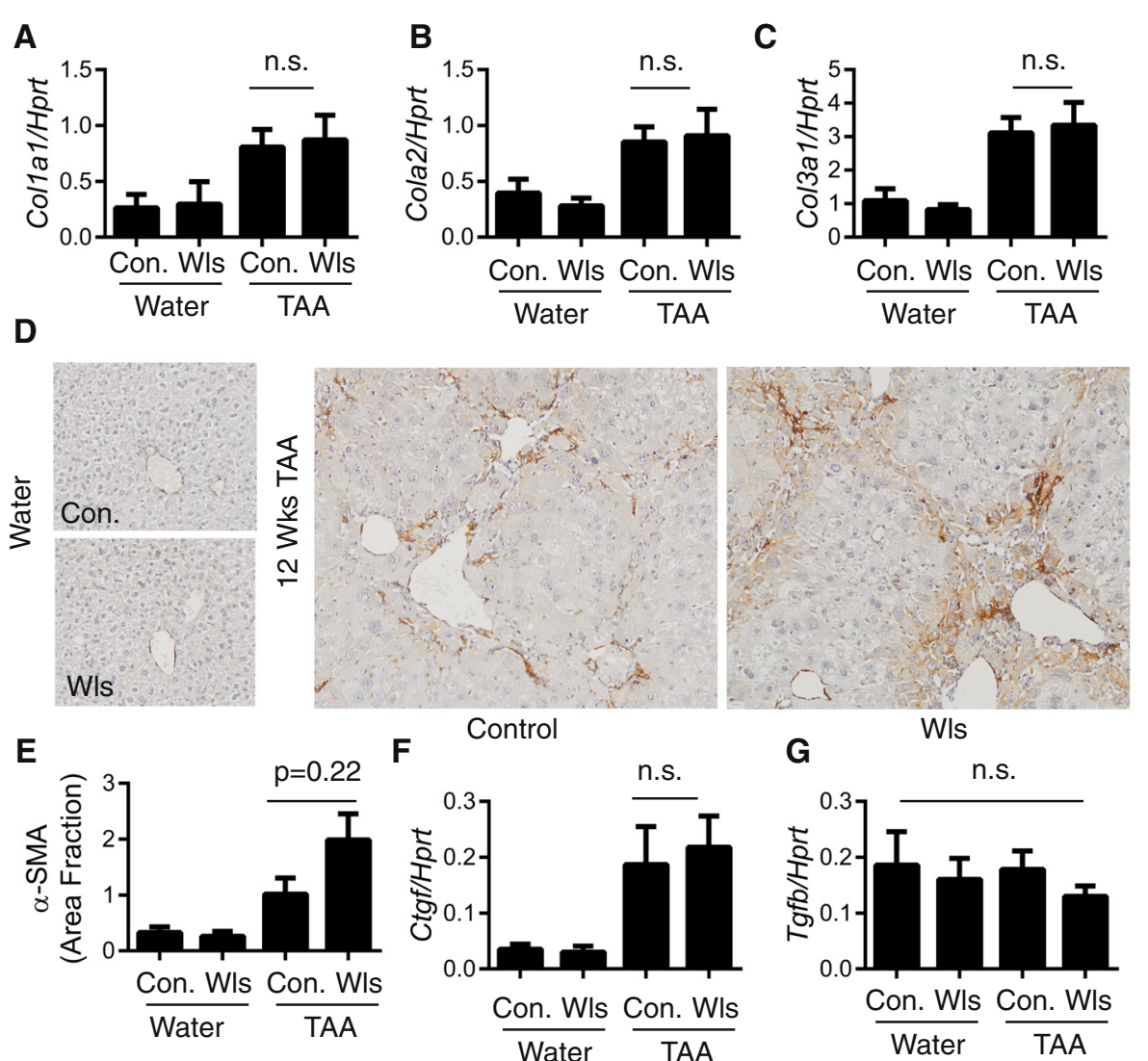

Fig. 5 Comparable myofibroblast activation in LysM-Wls and control mice. Whole liver expression of a Col1a1, b Co/1a2 and c Col3a1 in water- and 12-week TAA-treated control and LysM-Wls mice. $\mathbf{d}$ Representative SMA staining and e quantification of SMA staining (mean + SEM, $n=5$ per group) in livers from water- and 12-week TAA-treated control and LysM-Wls mice. Whole liver expression of $\mathbf{f}$ Ctgf and $\mathbf{g}$ Tgfb in water- and 12-week TAA-treated control and LysM-Wls mice. Data represent mean + SEM of 8-17 mice from 4 independent experiments. n.s. not significant

which likely have multiple potential target cells and mechanisms of action during chronic liver disease. We investigated the role of macrophage-derived Wnt proteins in fibrogenesis in two models of chronic liver disease and demonstrate that ablating Wls expression in myeloid cells exacerbated HPC activation and fibrosis.

Although the role of $\beta$-catenin in liver homeostasis and injury has been extensively studied [18], the contribution and sources of specific $\beta$-catenin-dependent Wnt proteins are little studied, and $\beta$-catenin-independent Wnt signalling is even less studied [27, 32, 39]. $\beta$-catenin is essential for hepatocyte-mediated liver regeneration after partial hepatectomy, and it was recently shown that macrophage- but not epithelium-derived Wnt proteins contribute to $\beta$-catenin activation in this setting [39]. A novel, $\beta$-catenin-dependent population of self-renewing hepatocytes maintained by endothelial-derived Wnts was also recently identified, although the role of these cells in liver injury has not yet been investigated [56]. In humans with acute liver failure, nuclear $\beta$-catenin localisation in hepatocytes correlated with patient survival and reduced requirement for liver transplant [29], consistent with a pro-regenerative role for $\beta$-catenin, although Wnt proteins were not directly implicated in this study. Interestingly, $\beta$-catenin depletion from mature hepatocytes in healthy mice caused HPC expansion, and hepatocytes were gradually replaced by $\beta$-catenin-positive HPC [57]. $\beta$-catenin has also been implicated in HPCmediated liver regeneration in murine chronic liver disease [30, 33], and hepatocyte-derived Wnt1 promoted HPC differentiation in rats, following partial hepatectomy and 2-acetylaminofluorene (AAF) treatment [32]. Our data demonstrating increased fibrosis and associated with more extensive ductular reactions and a more cholangiocytic HPC phenotype (increased Epcam and Trop2 expression) in LysM-Wls mice are consistent with a role for Wnt proteins in protecting from fibrosis by promoting HPC hepatocellular differentiation. However, we did not observe any difference in $\beta$-catenin localisation in livers from LysM-Wls and control mice. Whilst the $\beta$-catenin target gene Axin2 was reduced in whole liver in LysMWls mice, it was below the limit of detection in Epcam+ 


\section{A Whole liver}

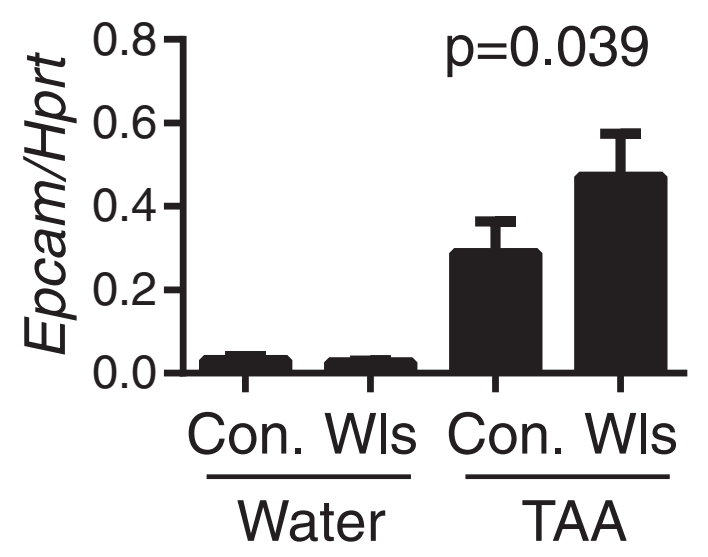

B Epcam+ cells

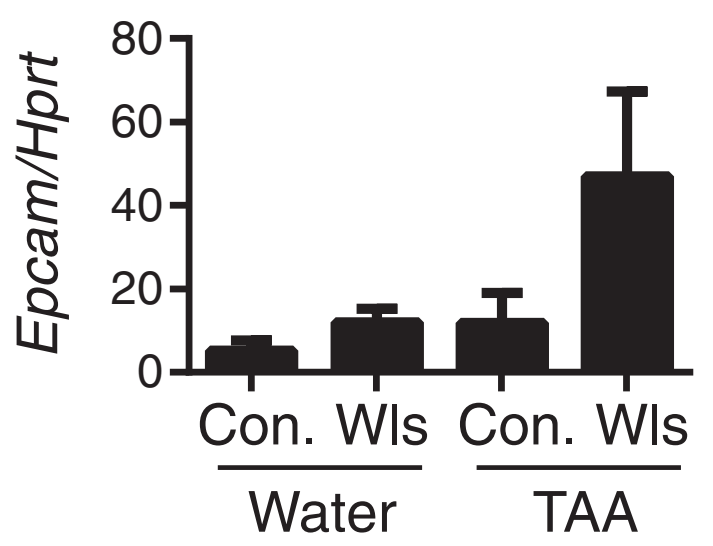

\section{Epcam+ Cells}

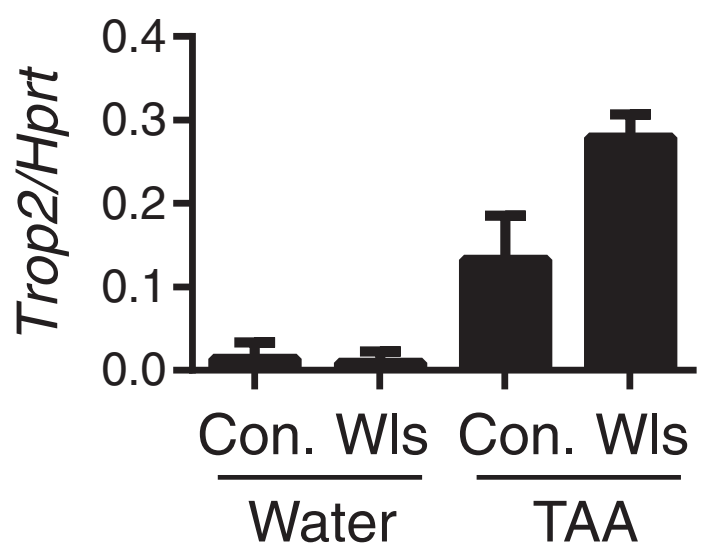

Fig. 6 Increased Epcam expression in Epcam+ cells from LysM-Wls mice. a Whole liver expression of Epcam in water- and 12-week TAA-treated control and LysM-WIs mice (mean + SEM of 8-17 mice from 4 independent experiments). Expression of $\mathbf{b}$ Epcam and $\mathbf{c}$ Trop 2 in flow cytometry-sorted Epcam + cells (pooled from 3 to 6 mice) from water- and 12-week TAA-treated control and LysM-Wls mice (mean + range of 2 independent experiments)

cells (which include HPC), so we could not ascertain whether this pathway was differentially activated in these cells in the absence of macrophage-derived Wnts. It is possible that cells with activated $\beta$-catenin signalling are not represented among the sorted population due to maturation-associated Epcam downregulation [45]. Alternatively, rather than representing a block in hepatocellular differentiation, the expanded DR observed in LysM-Wls mice could result from a pro-proliferative drive, via the activation of Hedgehog or other growth factors [58, 59], the persistence of collagen or altered matrix composition [11], or from hepatocyte metaplasia, rather than HPC activation [54].

In addition to their potential direct (or indirect) effects on HPC, macrophage-derived Wnts could influence HPC activation and fibrosis via additional target cells and mechanisms. Wnt $/ \beta$-Catenin signalling, for example, has been implicated in promoting stellate cell quiescence [60]; but we did not observe any difference in SMA expression or key cytokine regulators of myofibroblast activation, in LysMWls and control mice. In both the TAA and CDE models, increased hepatic collagen deposition in LysM-Wls mice occurred in the absence of increased expression of the key interstitial collagens, Col1a1, Col2a1 and Col3a1. In contrast to a typical pro-fibrogenic signature, with evidence of increased myofibroblast activation and collagen production, Timp1 mRNA, encoding a key hepatic Mmp inhibitor that prevents remodelling of the fibrotic scar [61, 62], was increased in LysM-Wls mice compared to littermate controls in both the TAA and CDE models. Moreover, in the TAA model, macrophage Mmp13 and Mmp12 expression was reduced in LysM-Wls mice. These data suggest the hypothesis that macrophage-derived Wnts promote fibrolysis, which dynamically counter-balances collagen accumulation, even during active fibrogenesis. The contribution of matrix remodelling to fibrogenesis during ongoing liver injury is not well understood, but studies altering the Timp to Mmp balance have consistently confirmed the potent influence of this ratio on the development and resolution of liver fibrosis [1]. Macrophages clearly play an essential role in the resolution of established fibrosis, after cessation of liver injury $[10,51,52]$. This involves reprogramming recruited monocytes/macrophages to a pro-resolution phenotype, including increased phagocytic activity and increased Mmp12 and Mmp13 expression, in conjunction with loss of liver Timp1 mRNA and protein expression [52]. Interestingly, 


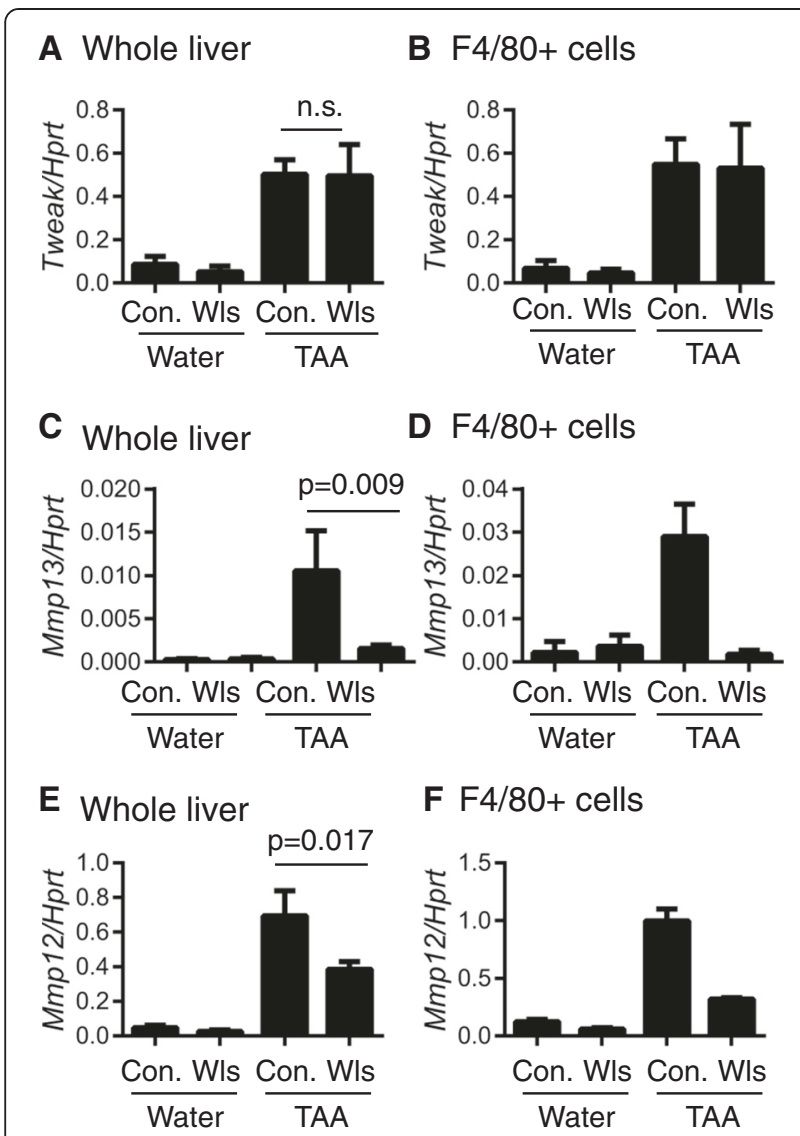

G Whole liver

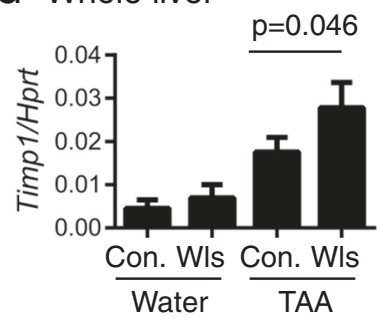

Fig. 7 Reduced macrophage matrix metalloproteinase expression in LysM-Wls mice. Tweak expression in $\mathbf{a}$ whole liver and $\mathbf{b}$ flow cytometry-sorted macrophages. Mmp13 expression in c whole liver and $\mathbf{d}$ flow cytometry-sorted macrophages, Mmp12 expression in e whole liver and $\mathbf{f}$ flow cytometry-sorted macrophages and $\mathbf{g}$ whole liver expression of Timp1 in water- and 12-week TAA-treated control and LysM-WIs mice. Data represent mean + SEM of 8-17 mice (whole liver) or mean + range of 2 independent experiments (sorted macrophages pooled from 3 to 6 mice in each experiment)

administration of bone marrow-derived macrophages during ongoing toxic injury was sufficient to ameliorate fibrosis, and this was associated with increased Mmp13 expression [13]. Similarly, Barnes and colleagues recently reported a reduced rate of collagen degradation, associated with reduced recruitment of macrophages to the fibrotic scar, and reduced Mmp13 activity during CCL4-induced liver injury in mice lacking the chemokine
MIF [63]. Mmp and Timp functions are not, however, limited to matrix proteolysis. Timp1 inhibits myofibroblast apoptosis [64], for example, whilst Mmp13 could contribute to fibrosis resolution via activation of latent hepatocyte growth factor and multiple downstream mechanisms [65-69]. Investigating the dynamic remodelling of multiple matrix components during chronic injury will be important to determine the functional relevance of the Timp1/ Mmp balance in different models at different stages of disease progression.

\section{Conclusions}

We have shown for the first time that the net effect of myeloid-derived Wnt proteins in chronic liver disease is to dampen HPC activation and fibrogenesis. Multiple Wnt proteins acting on different target cells may contribute to this phenotype, including direct effects on HPC fate, collagen-producing myofibroblasts and macrophages. Whilst Wnt induction, particularly leading to $\beta$-catenin activation, is not a viable therapeutic strategy in the setting of chronic liver disease, due to the risk of cancer development [70]; elucidation of the downstream pathways mediating Wnt proteins' anti-fibrogenic effects may reveal novel, specific therapeutic targets. Most significantly, however, these data suggest that pro- and antifibrogenic macrophage functions co-exist during disease progression and support the notion that reprogramming macrophages or otherwise enhancing anti-fibrogenic pathways may be a viable therapeutic strategy to ameliorate fibrogenesis during chronic liver disease.

\section{Methods}

\section{Transgenic mice and in vivo models}

All animal experiments were performed with approval from the University of Queensland Animal Ethics Committee (MED/PAH/156/13/PAHRF/NHMRC, UQDI/571/ 12/NHMRC/AIDRCC). To conditionally delete Wls from macrophages, homozygous Wls ${ }^{\text {flox/flox }}$ mice [40] were crossed with LysM-Cre transgenic mice [41] for 4-10 generations. Offspring with the genotype Wls ${ }^{\text {flox/flox }}$; LysMCre-positive represents Wls macrophage knockouts, whilst Wls ${ }^{\text {flox/flox }}$; LysM-Cre-negative was used as controls. Six to 9-week-old mice were administered with $30 \mathrm{mg} / \mathrm{L}$ thioacetamide (TAA, Sigma) in drinking water for 12 weeks [71] or a modified choline-deficient ethionine-supplemented (CDE) diet for 6 weeks [48], to induce chronic liver injury and fibrosis. The modified CDE diet was optimised by Professor George Yeoh [48] (UWA, Australia) and was custom made by MP Biosciences (Santa Ana, USA). The diet consisted of $70 \%$ choline-deficient diet (Cat\#0296021410) and $30 \%$ control (choline-sufficient) diet (Cat\#0296041210). At the end of the treatment period, mice were euthanised and a blood sample taken for serum isolation. Livers were perfused with 
$10 \mathrm{ml}$ of PBS via the portal vein in situ prior to tissue harvest to minimise blood contamination. Portions of the liver were fixed in $10 \%$ neutral buffered formalin and embedded in paraffin or homogenised in TRI reagent and stored at $-80{ }^{\circ} \mathrm{C}$ for RNA isolation. The remainder of the liver was used to isolate non-parenchymal cells. Serum ALT levels were measured using the MaxDiscovery Alanine Transaminase Color Endpoint Assay (Bioo Scientific, Austin, TX, USA).

\section{Non-parenchymal cell isolation}

Non-parenchymal cells were isolated by finely dissociating the liver tissue using surgical scissors then passing the fragments through a stainless steel strainer with the addition of $14 \mathrm{ml}$ of Hank's Based Salt Solution (HBSS) containing $1 \mathrm{mg} / \mathrm{ml}$ type 4 collagenase (Worthington Biochemical corporation, Lakewood, NJ, USA) $1 \mu \mathrm{g} / \mathrm{ml}$ DNase I (Sigma), $100 \mathrm{U} / \mathrm{ml}$ penicillin and $100 \mu \mathrm{g} / \mathrm{ml}$ streptomycin. The cell suspension was filtered through a $70-\mu \mathrm{M}$ filter (Becton Dickinson) and incubated at $37{ }^{\circ} \mathrm{C}$ for $5 \mathrm{~min}$, prior to the addition of $10 \mathrm{mM}$ EDTA and a further 5-min incubation period. The lysate was washed twice in cold PBS containing $2 \%$ FBS (FACS buffer) and resuspended in $25 \mathrm{ml}$ of $33 \%$ Percoll in PBS (isotonic) and centrifuged at $600 \times \mathrm{g}$ for $15 \mathrm{~min}$ with no brake. The supernatant was discarded and the pellet washed twice and resuspended in FACS buffer. Freshly isolated non-parenchymal cells $\left(\sim 5 \times 10^{6}\right)$ per liver were stained with anti-F4/80-PE (clone BM8) and anti-Epcam-APC (clone G8.8) (Biolegend) antibodies for $30 \mathrm{~min}$ at room temperature, washed twice and resuspended in FACS buffer for sorting. PEand APC-positive cells were sorted using an Astrios Moflo, achieving $>90 \%$ purity. Sorted cells were resuspended in TRI reagent (Sigma) for RNA purification.

\section{RNA purification and $\mathrm{qPCR}$}

RNA from whole liver $(5 \mu \mathrm{g})$ or sorted cells (entire yield) was transcribed to cDNA using oligodT priming and Superscript III (Life Technologies). Quantitative real-time PCR (qPCR) for genes of interest was performed using SYBR green (ABI) on an HT9000 or VIA-VII cycler with default cycle settings. Relative expression was determined using Hprt as housekeeping gene and the delta-Ct method and expressed as Target/Hprt. Primer sequences used in this study were the following: Hprt-F: TGCTGGATTA CATCAAAGCACTG, Hprt-R: CCCCTGTTGACTGGTC ATTACAA; Ccnd1-F CACAACGCACTTTCTTTCCAGA Cond1-R CTTGACTCCAGAAGGGCTTCAA Numb-F CAATGAGTTGCCTTCCACTATGC Numb-R ATCTGG GAACACAAGGAGCTGA Mmp12-F TACCCCAAGCT GATTTCCACAC Mmp12-R GCTCCTTGGAAGATGT AGTAGTGTCTTT Mmp13-F ACAAAGATTATCCCCG CCTCAT Mmp13-R GGCCCATTGAAAAAGTAGA TATAGCC Timp1-FAAGGGCTAAATTCATGGGTTCC
Timp1-R ACAGCCTTGAATCCTTTTAGCATC Mmp9-F AGGGGCGTGTCTGGAGATTC Mmp9-R TCCAGGG CACACCAGAGAAC Tweak-F CGCTCTTAGTCTGGTC CTGGTTT Tweak-R CACCAGTCTCCTCTATGGGG GTA Tgfb-F GTGGCTGAACCAAGGAGACG Tgfb-R GGCTGATCCCGTTGATTTCC F480-F CTGTCTGC TCAACCGTCAGGTA F480-R AGAAGTCTGGGAAT GGGAGCTAA E Epcam-F CGGGGATTGTTGTCCTG GTT Epcam-R GCACGGCTAGGCATTAAGCTC Trop2F AGGAGCTGGGGGAGATGAGA Trop2-R CCAACC CATCTGGTCTGAGG Krt19-F CCTAGCCAAGATCCTG AGTGAGAT Krt19-R TGGGTGTTCAGCTCCTCAATC Ctgf-F GTCAAGCTGCCTGGGAAATG Ctgf-R AATGT GTCTTCCAGTCGGTAGGC Il6-F GCTGGTGACAAC CACGGCCT Il6R GGCATAACGCACTAGGTTTGCCG Tnf-F AGGGGCCACCACGCTCTTCT Tnf-R CGGGG CAGCCTTGTCCCTTG Wls-F CAAATCGTTGCCTTTC TGGTG Wls-R TTGTCACACTTGTTAGGTCCC Wnt4-F AAGAGGAGACGTGCGAGAAA Wnt4-R CACCACCT TCCCAAAGACAG Wnt6-F TCAAGACTCTTTATGGA TGCGC Wnt6-R ATGGCACTTACACTCGGTG Sma-F GATCCTGACTGAGCGTGGCTAT Sma-R CGTGGCCA TCTCATTTTCAAAG mMmp2-F TTGCAGGAGACAA GTTCTGGAGATA mMmp2-R CACGACGGCATCCAG GTTAT mMmp8-F GGTTACCCCAAAAGCATACCAA mMmp8-R CACTGAAGAAGAGGAAGAAGGAGTC mCol1a2-F CACCCCAGCGAAGAACTCATAC mCol1a2R CCCCTTCTACGTTGTATTCAAACTG mCol3a1-F TGGGATCAAATGAAGGCGAAT mCol3a1-R GCTCCA TTCCCCAGTGTGTTTAG.

\section{Histology, immunohistochemistry and image analysis}

H\&E and Sirius red stains were performed and histological changes (inflammatory infiltrate and fibrosis) were assessed by two experienced hepatopathologists (GCM and ADC). Fibrosis stage was assessed using a modified METAVIR score as previously described [72]; briefly, stage 1: periportal or centrilobular fibrosis, stage 2: some septa, stage 3: many septa, stage 4: cirrhosis. Deparaffinised liver tissue sections were immunolabelled as described previously [73]. Antibodies used in this study were cytokeratin widespectrum screening (CKWSS, DAKO), F4/80 (Abcam), SMA (1A4, DAKO), $\beta$-catenin (Cell Signalling). HPC activation/ductular reactions were graded from CKWSSstained sections according to the following schema: 1 : CKWSS + cells surrounding $<50 \%$ of portal vein, 2: CKWSS+ cells surrounding $>50 \%$ of portal vein; 3 : CKWSS+ cells forming septa covering $<50 \%$ distance between two structures, 4: CKWSS+ cells forming septa covering $>50 \%$ distance between two structures. SMA and F4/80 image analysis were performed using ImageJ from ten captured images per section, each representing an area $310 \times 250 \mu \mathrm{m}$ in size. Sirius Red image analysis was performed using the positive pixel count algorithm 
in Aperio ImageScope from Aperio AT slide scans, from an area of $5-10 \mathrm{~mm}^{2}$ for each liver specimen. The algorithm was optimised to detect red pixels (hue value 0 , hue width 0.1 and colour saturation threshold 0.22 ). All portal tracts and central veins greater than $100 \mu \mathrm{m}$ in size were removed as they contain a large amount of collagen and therefore prevent quantification of fibrosis-associated collagen.

\section{Statistical analysis}

Group comparisons were performed using the MannWhitney- $U$ test. A two-tailed $p$ value of 0.05 was considered statistically significant. All statistical analyses were performed using Prism Version 6 (GraphPad).

\section{Additional files}

Additional file 1: Figure S1. W/s depletion and Wnt expression in WIs-loxp $\times$ LysM-Cre mice. (A) RT-PCR quantification of Wls expression in bone marrow-derived macrophages from Wlsfl/fl and LysM-Cre+/- mice ( $n=4-5$, Mann-Whitney- $U$ test). (B) Flow cytometry gating strategy for sorting F4/80+ and Epcam+ cells from liver non-parenchymal cells. Post-sort analysis of (C) F4/80+ and (D) Epcam+ cells. RT-PCR quantification of W/s expression in sorted (E) F4/80+ and (F) Epcam+ cells from control and 12-week TAA-treated mice. RT-PCR quantification of (G) Wnt4 and (H) Wnt6 expression in sorted F4/80+ cells from control and 12-week TAA-treated mice. Sorted cells were pooled from 3 to 6 mice from control and LysM-WIs mice. Data represent mean + range of 2 independent experiments. (EPS $1589 \mathrm{~kb}$ )

Additional file 2: Figure S2. Increased ductular reaction and fibrosis in male LysM-Wls mice compared to littermate controls. (A) Ductular reaction grade, (B) fibrosis score and (C) whole liver Colla1 expression in livers from water- and 12-week TAA-treated control and LysM-WIs male mice. Data represent mean + SEM of 4-8 mice from 3 independent experiments. (EPS $478 \mathrm{~kb}$ )

Additional file 3: Figure S3. Increased ductular reaction and fibrosis in LysM-WIs mice in the CDE model of chronic liver disease. Ductular reaction grade (A), fibrosis score (B) and whole liver expression of Collal (D), Col3al (E), Sma (F), Epcam (G) and Timp1 (I) in livers from LysM-Wls and control mice fed with a CDE diet for 6 weeks. Data represent mean $+\operatorname{SEM}$ from $n=3$ mice from 1 experiment, representative of 3 independent experiments. (H) Epcam expression in flow cytometry-sorted Epcam+ cells (pooled from 3 mice) from LysM-WIs and control mice treated fed with a CDE diet for 6 weeks. Data represent mean + range of PCR duplicates, representative of 3 independent experiments. (EPS $509 \mathrm{~kb}$ )

\section{Abbreviations}

CDE: Choline-deficient ethionine-supplemented; CLD: Chronic liver disease; DR: Ductular reaction; HPC: Hepatic progenitor cells; TAA: Thioacetamide.

\section{Competing interests}

The authors declare that they have no competing interests.

\section{Authors' contributions}

$\mathrm{KMI}, \mathrm{AB}$ and EEP conceived and designed the study. KMI, WW, VLG, MRM, MM, KM, MJS and RL developed techniques and/or produced data. KMI, $A D C, G M$ and VLG analysed the data. RL and MJS provided essential reagents and critical review. KMI, ADC, AB and EEP wrote the manuscript. All authors read and approved the final manuscript.

\section{Acknowledgements}

We wish to acknowledge Professor George Yeoh for advice on the CDE model and helpful discussions, Ms. Tam Ngyuen for genotyping macrophage analyses, and the Translational Research Institute Flow Cytometry and Biological Resources Facilities for technical assistance. This study was funded by project grants from the Princess Alexandra Hospital Foundation and the National Health and Medical
Research Council (NHMRC), Australia. EEP is supported by an NHMRC Practitioner Fellowship and KMI is supported by an Australian Liver Foundation Fellowship.

\section{Author details}

${ }^{1}$ Centre for Liver Disease Research, School of Medicine, The University of Queensland, Translational Research Institute, 37 Kent St, Brisbane 4102, Australia. ${ }^{2}$ QIMR Berghofer Medical Research Institute, Brisbane, Australia. ${ }^{3}$ The University of Queensland Diamantina Institute, Translational Research Institute, Brisbane, Australia. 'Visual Systems Group, Cincinnati Children's Hospital Medical Center, Cincinnati, OH, USA. ${ }^{5}$ Institute for Molecular Bioscience and the Centre for Inflammation and Disease Research, The University of Queensland, Brisbane, Australia. ${ }^{6}$ Australian Infectious Diseases Research Centre, The University of Queensland, Brisbane, Australia.

Received: 9 June 2015 Accepted: 17 September 2015

Published online: 15 October 2015

\section{References}

1. Iredale JP, Thompson A, Henderson NC. Extracellular matrix degradation in liver fibrosis: biochemistry and regulation. Biochim Biophys Acta. 2013;1832(7):876-83. doi:10.1016/j.bbadis.2012.11.002.

2. Williams MJ, Clouston AD, Forbes SJ. Ductular reactions and fibrosis: what is the link and can we break it? Gastroenterology. 2013 (Submitted).

3. Gouw AS, Clouston AD, Theise ND. Ductular reactions in human liver: diversity at the interface. Hepatology. 2011;54(5):1853-63. doi:10.1002/ hep.24613.

4. Williams MJ, Clouston AD, Forbes SJ. Links between hepatic fibrosis, ductular reaction, and progenitor cell expansion. Gastroenterology. 2014;146(2):349-56. doi:10.1053/j.gastro.2013.11.034.

5. Espanol-Suner R, Carpentier R, Van HN, Legry V, Achouri Y, Cordi S, et al. Liver progenitor cells yield functional hepatocytes in response to chronic liver injury in mice. Gastroenterology. 2012;143(6):1564-75. doi:10.1053/ j.gastro.2012.08.024.

6. Malato Y, Naqvi S, Schurmann N, Ng R, Wang B, Zape J, et al. Fate tracing of mature hepatocytes in mouse liver homeostasis and regeneration. J Clin Invest. 2011;121(12):4850-60. doi:10.1172/JCI59261.

7. Lu WY, Bird TG, Boulter L, Tsuchiya A, Cole AM, Hay T, et al. Hepatic progenitor cells of biliary origin with liver repopulation capacity. Nat Cell Biol. 2015;17(8):971-83. doi:10.1038/ncb3203.

8. Gadd VL, Melino M, Roy S, Horsfall L, O'Rourke P, Williams MR, et al. Portal, but not lobular, macrophages express MMP-9: association with the ductular reaction and fibrosis in chronic HCV. Liver Int. 2013;33(4):569-79. doi:10.1111/liv.12050.

9. Gadd VL, Skoien R, Powell EE, Fagan KJ, Winterford C, Horsfall L, et al. The portal inflammatory infiltrate and ductular reaction in human non-alcoholic fatty liver disease. Hepatology. 2013. doi:10.1002/hep.26937.

10. Duffield JS, Forbes SJ, Constandinou CM, Clay S, Partolina M, Vuthoori S, et al. Selective depletion of macrophages reveals distinct, opposing roles during liver injury and repair. J Clin Invest. 2005;115(1):56-65. doi:10.1172/ JCl22675.

11. Lorenzini S, Bird TG, Boulter L, Bellamy C, Samuel K, Aucott R, et al. Characterisation of a stereotypical cellular and extracellular adult liver progenitor cell niche in rodents and diseased human liver. Gut. 2010;59(5):645-54. doi:10.1136/gut.2009.182345.

12. Kantari-Mimoun C, Castells M, Klose R, Meinecke AK, Lemberger UJ, Rautou $P E$, et al. Resolution of liver fibrosis requires myeloid cell-driven sinusoidal angiogenesis. Hepatology. 2014. doi:10.1002/hep.27635.

13. Thomas JA, Pope C, Wojtacha D, Robson AJ, Gordon-Walker TT, Hartland S, et al. Macrophage therapy for murine liver fibrosis recruits host effector cells improving fibrosis, regeneration, and function. Hepatology. 2011;53(6):2003-15. doi:10.1002/hep.24315.

14. Boulter L, Govaere O, Bird TG, Radulescu S, Ramachandran P, Pellicoro A, et al. Macrophage-derived Wnt opposes Notch signaling to specify hepatic progenitor cell fate in chronic liver disease. Nat Med. 2012;18(4):572-9. doi:10.1038/nm.2667.

15. Bird TG, Lu WY, Boulter L, Gordon-Keylock S, Ridgway RA, Williams MJ, et al. Bone marrow injection stimulates hepatic ductular reactions in the absence of injury via macrophage-mediated TWEAK signaling. Proc Natl Acad Sci U S A. 2013;110(16):6542-7. doi:10.1073/pnas.1302168110.

16. Van HN, Lanthier N, Espanol SR, Abarca QJ, van Rooijen N, Leclercq I. Kupffer cells influence parenchymal invasion and phenotypic orientation, 
but not the proliferation, of liver progenitor cells in a murine model of liver injury. Am J Pathol. 2011;179(4):1839-50. doi:10.1016/j.ajpath.2011.06.042.

17. Spee B, Carpino G, Schotanus BA, Katoonizadeh A, Vander BS, Gaudio E, et al. Characterisation of the liver progenitor cell niche in liver diseases: potential involvement of Wnt and Notch signalling. Gut. 2010;59(2):247-57 doi:10.1136/gut.2009.188367.

18. Nejak-Bowen KN, Monga SP. Beta-catenin signaling, liver regeneration and hepatocellular cancer: sorting the good from the bad. Semin Cancer Biol. 2011;21(1):44-58. doi:10.1016/j.semcancer.2010.12.010.

19. Boulter L, Guest RV, Kendall TJ, Wilson DH, Wojtacha D, Robson AJ, et al. WNT signaling drives cholangiocarcinoma growth and can be pharmacologically inhibited. J Clin Invest. 2015;125(3):1269-85. doi:10.1172/JCI76452.

20. Yeoh GC, Ernst M, Rose-John S, Akhurst B, Payne C, Long S, et al. Opposing roles of gp130-mediated STAT-3 and ERK-1/2 signaling in liver progenitor cell migration and proliferation. Hepatology. 2007:45(2):486-94. doi:10.1002/hep.21535.

21. Subrata LS, Lowes KN, Olynyk JK, Yeoh GC, Quail EA, Abraham LJ. Hepatic expression of the tumor necrosis factor family member lymphotoxin-beta is regulated by interleukin (IL)- 6 and IL-1 beta: transcriptional control mechanisms in oval cells and hepatoma cell lines. Liver Int. 2005;25(3):633-46. doi:10.1111/ j.1478-3231.2005.01080.x.

22. Knight B, Yeoh GC, Husk KL, Ly T, Abraham $\sqcup$, Yu C, et al. Impaired preneoplastic changes and liver tumor formation in tumor necrosis factor receptor type 1 knockout mice. J Exp Med. 2000;192(12):1809-18.

23. Knight B, Lim R, Yeoh GC, Olynyk JK. Interferon-gamma exacerbates liver damage, the hepatic progenitor cell response and fibrosis in a mouse model of chronic liver injury. J Hepatol. 2007;47(6):826-33. doi:10.1016/j.jhep.2007.06.022.

24. Tirnitz-Parker JE, Viebahn CS, Jakubowski A, Klopcic BR, Olynyk JK, Yeoh GC, et al. Tumor necrosis factor-like weak inducer of apoptosis is a mitogen for liver progenitor cells. Hepatology. 2010;52(1):291-302. doi:10.1002/hep.23663.

25. Paku S, Schnur J, Nagy P, Thorgeirsson SS. Origin and structural evolution of the early proliferating oval cells in rat liver. Am J Pathol. 2001;158(4):1313-23. doi:10.1016/S0002-9440(10)64082-5.

26. Kallis YN, Robson AJ, Fallowfield JA, Thomas HC, Alison MR, Wright NA, et al. Remodelling of extracellular matrix is a requirement for the hepatic progenitor cell response. Gut. 2011;60(4):525-33. doi:10.1136/gut.2010.224436.

27. Wang S, Song K, Srivastava R, Dong C, Go GW, Li N, et al. Nonalcoholic fatty liver disease induced by noncanonical Wnt and its rescue by Wnt3a. FASEB J. 2015:29(8):3436-45. doi:10.1096/fi.15-271171.

28. Monga SP. Role and regulation of beta-catenin signaling during physiological liver growth. Gene Expr. 2014;16(2):51-62. doi:10.3727/ $105221614 X 13919976902138$.

29. Apte U, Singh S, Zeng G, Cieply B, Virji MA, Wu T, et al. Beta-catenin activation promotes liver regeneration after acetaminophen-induced injury. Am J Pathol. 2009;175(3):1056-65. doi:10.2353/ajpath.2009.080976.

30. Apte U, Thompson MD, Cui S, Liu B, Cieply B, Monga SP. Wnt/beta-catenin signaling mediates oval cell response in rodents. Hepatology. 2008:47(1):288-95. doi:10.1002/hep.21973.

31. Hu M, Kurobe M, Jeong YJ, Fuerer C, Ghole S, Nusse R, et al. Wnt/betacatenin signaling in murine hepatic transit amplifying progenitor cells. Gastroenterology. 2007;133(5):1579-91. doi:10.1053/j.gastro.2007.08.036.

32. Williams JM, Oh SH, Jorgensen M, Steiger N, Darwiche H, Shupe T, et al. The role of the Wnt family of secreted proteins in rat oval 'stem' cell-based liver regeneration: Wnt1 drives differentiation. Am J Pathol. 2010;176(6):2732-42. doi:10.2353/ajpath.2010.080486

33. Itoh T, Kamiya Y, Okabe M, Tanaka M, Miyajima A. Inducible expression of Wnt genes during adult hepatic stem/progenitor cell response. FEBS Lett. 2009;583(4):777-81. doi:10.1016/j.febslet.2009.01.022.

34. Thompson MD, Awuah P, Singh S, Monga SP. Disparate cellular basis of improved liver repair in beta-catenin-overexpressing mice after long-term exposure to 3,5-diethoxycarbonyl-1,4-dihydrocollidine. Am J Pathol. 2010;177(4):1812-22. doi:10.2353/ajpath.2010.100173.

35. Akhmetshina A, Palumbo K, Dees C, Bergmann C, Venalis $P$, Zerr $P$, et al. Activation of canonical Wnt signalling is required for TGF-beta-mediated fibrosis. Nat Commun. 2012;3:735. doi:10.1038/ncomms1734.

36. Henderson Jr WR, Chi EY, Ye X, Nguyen C, Tien YT, Zhou B, et al. Inhibition of Wnt/beta-catenin/CREB binding protein (CBP) signaling reverses pulmonary fibrosis. Proc Natl Acad Sci U S A. 2010;107(32):14309-14. doi:10.1073/ pnas. 1001520107.

37. Beyer C, Schramm A, Akhmetshina A, Dees C, Kireva T, Gelse K, et al. betacatenin is a central mediator of pro-fibrotic Wnt signaling in systemic sclerosis. Ann Rheum Dis. 2012;71(5):761-7. doi:10.1136/annrheumdis-2011-200568.
38. Hao S, He W, Li Y, Ding H, Hou Y, Nie J, et al. Targeted inhibition of beta-catenin/ CBP signaling ameliorates renal interstitial fibrosis. J Am Soc Nephrol. 2011;22(9):1642-53. doi:10.1681/ASN.2010101079.

39. Yang J, Mowry LE, Nejak-Bowen KN, Okabe H, Diegel CR, Lang RA, et al. Beta-catenin signaling in murine liver zonation and regeneration: a WntWnt situation! Hepatology. 2014;60(3):964-76. doi:10.1002/hep.27082.

40. Carpenter AC, Rao S, Wells JM, Campbell K, Lang RA. Generation of mice with a conditional null allele for Wntless. Genesis. 2010;48(9):554-8. doi:10.1002/dvg.20651.

41. Clausen BE, Burkhardt C, Reith W, Renkawitz R, Forster I. Conditional gene targeting in macrophages and granulocytes using LysMcre mice. Transgenic Res. 1999;8(4):265-77.

42. Pradere JP, Kluwe J, De Minicis S, Jiao JJ, Gwak GY, Dapito DH, et al. Hepatic macrophages but not dendritic cells contribute to liver fibrosis by promoting the survival of activated hepatic stellate cells in mice. Hepatology. 2013:58(4):1461-73. doi:10.1002/hep.26429.

43. Karsdal MA, Manon-Jensen T, Genovese F, Kristensen JH, Nielsen MJ, Sand $J M$, et al. Novel insights into the function and dynamics of extracellular matrix in liver fibrosis. Am J Physiol Gastrointest Liver Physiol. 2015;308(10):G807-30. doi:10.1152/ajpgi.00447.2014.

44. Wang Q, Usinger W, Nichols B, Gray J, Xu L, Seeley TW, et al. Cooperative interaction of CTGF and TGF-beta in animal models of fibrotic disease. Fibrogenesis Tissue Repair. 2011;4(1):4. doi:10.1186/1755-1536-4-4.

45. Dolle L, Theise ND, Schmelzer E, Boulter L, Gires O, van Grunsven LA. EpCAM and the biology of hepatic stem/progenitor cells. Am J Physiol Gastrointest Liver Physiol. 2015;308(4):G233-G50. doi:10.1152/ajpgi.00069.2014.

46. Okabe M, Tsukahara Y, Tanaka M, Suzuki K, Saito S, Kamiya Y, et al. Potential hepatic stem cells reside in EpCAM+ cells of normal and injured mouse liver. Development. 2009;136(11):1951-60. doi:10.1242/dev.031369.

47. Wynn TA, Barron L. Macrophages: master regulators of inflammation and fibrosis. Semin Liver Dis. 2010;30(3):245-57. doi:10.1055/s-0030-1255354.

48. Akhurst B, Croager EJ, Farley-Roche CA, Ong JK, Dumble ML, Knight B, et al. A modified choline-deficient, ethionine-supplemented diet protocol effectively induces oval cells in mouse liver. Hepatology. 2001;34(3):519-22. doi:10.1053/jhep.2001.26751.

49. Karlmark KR, Zimmermann HW, Roderburg C, Gassler N, Wasmuth HE, Luedde $\mathrm{T}$, et al. The fractalkine receptor CXCR1 protects against liver fibrosis by controlling differentiation and survival of infiltrating hepatic monocytes. Hepatology. 2010;52(5):1769-82. doi:10.1002/hep.23894.

50. Dal-Secco D, Wang J, Zeng Z, Kolaczkowska E, Wong CH, Petri B, et al. A dynamic spectrum of monocytes arising from the in situ reprogramming of CCR2+ monocytes at a site of sterile injury. J Exp Med. 2015;212(4):447-56. doi:10.1084/jem.20141539.

51. Ramachandran P, Iredale JP. Macrophages: central regulators of hepatic fibrogenesis and fibrosis resolution. J Hepatol. 2012. doi:10.1016//.jhep.2011.10.026.

52. Ramachandran P, Pellicoro A, Vernon MA, Boulter L, Aucott RL, Ali A, et al. Differential $L y-6 C$ expression identifies the recruited macrophage phenotype, which orchestrates the regression of murine liver fibrosis. Proc Natl Acad Sci U S A. 2012;109(46):E3186-95. doi:10.1073/pnas.1119964109.

53. Huch M, Dorrell C, Boj SF, van EJH, Li VS, van dWM, et al. In vitro expansion of single Lgr5+ liver stem cells induced by Wnt-driven regeneration. Nature. 2013:494(7436):247-50. doi:10.1038/nature11826.

54. Yimlamai D, Christodoulou C, Galli GG, Yanger K, Pepe-Mooney B, Gurung B, et al. Hippo pathway activity influences liver cell fate. Cell. 2014;157(6):1324-38. doi:10.1016/j.cell.2014.03.060

55. Michalopoulos GK, Barua L, Bowen WC. Transdifferentiation of rat hepatocytes into biliary cells after bile duct ligation and toxic biliary injury. Hepatology. 2005;41(3):535-44. doi:10.1002/hep.20600.

56. Wang B, Zhao L, Fish M, Logan CY, Nusse R. Self-renewing diploid Axin2(+) cells fuel homeostatic renewal of the liver. Nature. 2015;524(7564):180-5. doi:10.1038/nature14863.

57. Wang EY, Yeh SH, Tsai TF, Huang HP, Jeng YM, Lin WH, et al. Depletion of beta-catenin from mature hepatocytes of mice promotes expansion of hepatic progenitor cells and tumor development. Proc Natl Acad Sci U S A. 2011;108(45):18384-9. doi:10.1073/pnas.1116386108.

58. Winkler T, Mahoney EJ, Sinner D, Wylie CC, Dahia CL. Wnt signaling activates Shh signaling in early postnatal intervertebral discs, and re-activates Shh signaling in old discs in the mouse. PLoS One. 2014;9(6):e98444. doi:10.1371/ journal.pone.0098444.

59. Michelotti GA, Xie G, Swiderska M, Choi SS, Karaca G, Kruger L, et al. Smoothened is a master regulator of adult liver repair. J Clin Invest. 2013;123(6):2380-94. doi:10.1172/JCl66904. 
60. Kordes C, Sawitza I, Haussinger D. Canonical Wnt signaling maintains the quiescent stage of hepatic stellate cells. Biochem Biophys Res Commun. 2008;367(1):116-23. doi:10.1016/j.bbrc.2007.12.085.

61. Yoshiji H, Kuriyama S, Yoshii J, Ikenaka Y, Noguchi R, Nakatani T, et al. Tissue inhibitor of metalloproteinases-1 attenuates spontaneous liver fibrosis resolution in the transgenic mouse. Hepatology. 2002;36(4 Pt 1):850-60. doi:10.1053/jhep.2002.35625.

62. Parsons CJ, Bradford BU, Pan CQ, Cheung E, Schauer M, Knorr A, et al. Antifibrotic effects of a tissue inhibitor of metalloproteinase-1 antibody on established liver fibrosis in rats. Hepatology. 2004;40(5):1106-15. doi:10.1002/ hep.20425.

63. Barnes MA, McMullen MR, Roychowdhury S, Madhun NZ, Niese K, Olman $M A$, et al. Macrophage migration inhibitory factor is required for recruitment of scar-associated macrophages during liver fibrosis. J Leukoc Biol. 2015;97(1):161-9. doi:10.1189/jlb.3A0614-280R.

64. Pellicoro A, Ramachandran P, Iredale JP, Fallowfield JA. Liver fibrosis and repair: immune regulation of wound healing in a solid organ. Nat Rev Immunol. 2014;14(3):181-94. doi:10.1038/nri3623.

65. Endo H, Niioka M, Sugioka Y, Itoh J, Kameyama K, Okazaki I, et al. Matrix metalloproteinase-13 promotes recovery from experimental liver cirrhosis in rats. Pathobiology. 2011;78(5):239-52. doi:10.1159/000328841.

66. Kim WH, Matsumoto K, Bessho K, Nakamura T. Growth inhibition and apoptosis in liver myofibroblasts promoted by hepatocyte growth factor leads to resolution from liver cirrhosis. Am J Pathol. 2005;166(4):1017-28. doi:10.1016/S0002-9440(10)62323-1.

67. Marquardt JU, Seo D, Gomez-Quiroz LE, Uchida K, Gillen MC, Kitade M, et al. Loss of c-Met accelerates development of liver fibrosis in response to CCI(4) exposure through deregulation of multiple molecular pathways. Biochim Biophys Acta. 2012;1822(6):942-51. doi:10.1016/j.bbadis.2012.02.012.

68. Suzumura K, Hirano T, Son G, limuro Y, Mizukami H, Ozawa K, et al. Adenoassociated virus vector-mediated production of hepatocyte growth factor attenuates liver fibrosis in mice. Hepatol Int. 2008;2(1):80-8. doi:10.1007/ s12072-007-9042-1.

69. Ishikawa T, Factor VM, Marquardt JU, Raggi C, Seo D, Kitade M, et al. Hepatocyte growth factor/c-met signaling is required for stem-cellmediated liver regeneration in mice. Hepatology. 2012;55(4):1215-26. doi:10.1002/hep.24796.

70. Zulehner G, Mikula M, Schneller D, van Zijl F, Huber H, Sieghart W, et al. Nuclear beta-catenin induces an early liver progenitor phenotype in hepatocellular carcinoma and promotes tumor recurrence. Am J Pathol. 2010;176(1):472-81. doi:10.2353/ajpath.2010.090300

71. Wallace MC, Hamesch K, Lunova M, Kim Y, Weiskirchen R, Strnad P, et al. Standard operating procedures in experimental liver research: thioacetamide model in mice and rats. Lab Anim. 2015:49(1 Suppl):21-9. doi:10.1177/ 0023677215573040

72. Fagan KJ, Pretorius CJ, Horsfall LU, Irvine KM, Wilgen U, Choi K, et al. ELF score $>/=9.8$ indicates advanced hepatic fibrosis and is influenced by age, steatosis and histological activity. Liver Int. 2014. doi:10.1111/liv.12760.

73. Gadd VL, Melino M, Roy S, Horsfall L, O'Rourke P, Williams MR, et al. Portal, but not lobular, macrophages express matrix metalloproteinase-9: association with the ductular reaction and fibrosis in chronic hepatitis C. Liver Int. 2013;33(4):569-79. doi:10.1111/liv.12050

\section{Submit your next manuscript to BioMed Central and take full advantage of:}

- Convenient online submission

- Thorough peer review

- No space constraints or color figure charges

- Immediate publication on acceptance

- Inclusion in PubMed, CAS, Scopus and Google Scholar

- Research which is freely available for redistribution 